\title{
Epigenetic events underlie the pathogenesis of sinonasal papillomas
}

\author{
Josena K Stephen ${ }^{1}$, Lori E Vaught ${ }^{1}$, Kang M Chen ${ }^{1}$, Seema Sethi ${ }^{1}$, Veena Shah ${ }^{2}$, \\ Michael S Benninger ${ }^{1}$, Glendon M Gardner ${ }^{1}$, Vanessa G Schweitzer ${ }^{1}$, Mumtaz Khan ${ }^{1}$ \\ and Maria J Worsham ${ }^{1}$
}

${ }^{1}$ Department of Otolaryngology/Head and Neck Surgery, Henry Ford Hospital, Detroit, MI, USA and ${ }^{2}$ Department of Pathology, Henry Ford Hospital, Detroit, MI, USA

\begin{abstract}
Benign inverted papillomas have been reported as monoclonal but lacking common genetic alterations identified in squamous cell carcinoma of the head and neck. Epigenetic changes alter the heritable state of gene expression and chromatin organization without change in DNA sequence. We investigated whether epigenetic events of aberrant promoter hypermethylation in genes known to be involved in squamous head and neck cancer underlie the pathogenesis of sinonasal papillomas. Ten formalin-fixed paraffin DNA samples from three inverted papilloma cases, two exophytic (everted) papilloma cases, and two cases with inverted and exophytic components were studied. DNA was obtained from microdissected areas of normal and papilloma areas and examined using a panel of $\mathbf{4 1}$ gene probes, designed to interrogate 35 unique genes for aberrant methylation status (22 genes) using the methylation-specific multiplex-ligation-specific polymerase assay. Methylationspecific PCR was employed to confirm aberrant methylation detected by the methylation-specific multiplexligation-specific polymerase assay. All seven cases indicated at least one epigenetic event of aberrant promoter hypermethylation. The CDKN2B gene was a consistent target of aberrant methylation in six of seven cases. Methylation-specific PCR confirmed hypermethylation of CDKN2B. Recurrent biopsies from two inverted papilloma cases had common epigenetic events. Promoter hypermethylation of CDKN2B was a consistent epigenetic event. Common epigenetic alterations in recurrent biopsies underscore a monoclonal origin for these lesions. Epigenetic events contribute to the underlying pathogenesis of benign inverted and exophytic papillomas. As a consistent target of aberrant promoter hypermethylation, CDKN2B may serve as an important epigenetic biomarker for gene reactivation studies.
\end{abstract}

Modern Pathology (2007) 20, 1019-1027; doi:10.1038/modpathol.3800944; published online 3 August 2007

Keywords: sinonasal papillomas; inverted papillomas; promoter hypermethylation; methylation-specific multiplexligation-specific polymerase assay; methylation-specific PCR; epigenetics

Sinonasal papillomas have been categorized histologically as inverted, fungiform (exophytic), and cylindrical cell papillomas (also commonly known as oncocytic schneiderian papilloma). ${ }^{1}$ Although there is debate about the correct nomenclature, based on the pattern of growth, these papillomas can be grouped as either endophytic (consisting of inverted and cylindrical cell papillomas) or exophytic (fungiform papillomas). Inverted papillomas are the most commonly occurring sinonasal papillomas followed by exophytic. ${ }^{2}$ Inverted papillomas arise

Correspondence: MJ Worsham, PhD, FACMG, Department of Otolaryngology/Head and Neck Research, Wayne State School of Medicine, Henry Ford Hospital, 1 Ford Place, 1D, Detroit, MI 48202, USA.

E-mail: mworsha1@hfhs.org

Received 24 January 2007; revised 22 June 2007; accepted 25 June 2007; published online 3 August 2007 from the lateral wall of the nose and paranasal sinuses and are associated with invasive squamous cell carcinoma (SCC). Its surface epithelium invaginates into the underlying stroma (Figure 1a), thus the name inverted (endophytic) papilloma. Exophytic papillomas arise exclusively from the nasal septum. They contain connective tissue stalks producing an everted (exophytic or mushroomshaped) lesion (Figure 1b). Cylindrical cell papillomas are relatively uncommon, have an inverted growth pattern, mainly arise from the lateral wall of the nose and have higher rates of recurrence and malignant transformation to SCC.

Recurrence rates vary widely, ranging from 6 to $33 \%$, despite management by different surgical treatment options. ${ }^{3}$ Recurrences are most likely due to incomplete local resection considering that many recur early and at the site of the original tumor. Morphology is not useful in determining if a 
a

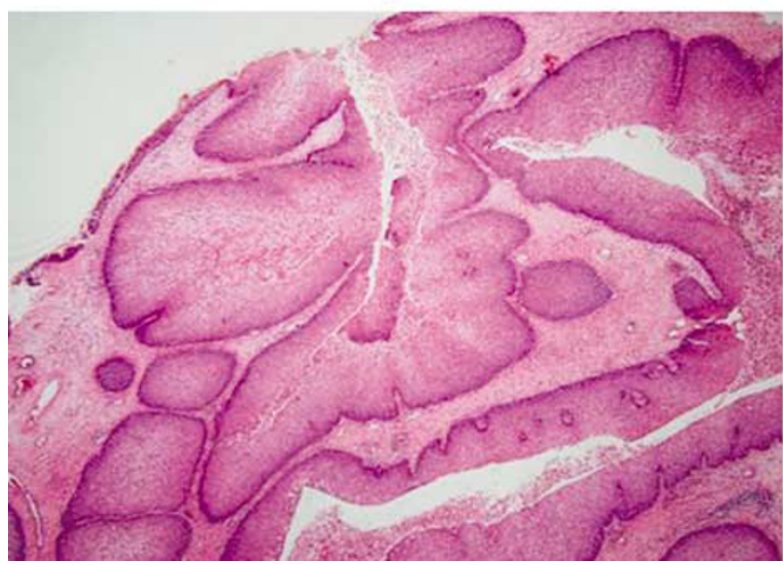

Figure 1 (a) Inverted papilloma. (b) Exophytic papilloma.

lesion will recur or acquire malignant changes. A general belief is that once excised, and in the absence of malignancy in the excised specimen, a recurrence is unlikely to convert into malignancy. ${ }^{4}$ Search for additional methods to adequately aid in predicting recurrence or malignancy of sinonasal papillomas has clinical utility.

Human papilloma virus (HPV) is frequently associated with nasal papillomas. Studies have found HPV DNA in $50-100 \%$ of tested septal (exophytic) papillomas ${ }^{5}$ and in $0-86 \%$ of lateral wall (inverted) papillomas. ${ }^{6}$ Buchwald et al ${ }^{7}$ determined that $13 \%$ of their cases of SCC associated with inverted papilloma were HPV positive. Most HPV-positive cases of sinonasal papillomas are of the inverted papilloma type. ${ }^{8}$ Benign papillomas are preferentially associated with the low-risk HPV types 6 and 11, whereas their malignant counterparts are exclusively positive for HPV-16 DNA. ${ }^{9}$ Therefore, HPV infection may be an early event in a multistep process of malignant formation of inverted papillomas. ${ }^{10}$

Benign inverted papillomas were reported as monoclonal but lacking common genetic alterations associated with squamous head and neck cancer. ${ }^{4}$ Epigenetic changes alter the heritable state of gene expression and chromatin organization without change in DNA sequence. DNA methylation events are increasingly thought of as diagnostic markers for certain tumor types or stages underscoring promoter hypermethylation events as potential epigenetic biomarkers. Loss of $\mathrm{p} 16^{\mathrm{INK} 4 \mathrm{a}}$ and $\mathrm{p} 15^{\mathrm{INK} 4 \mathrm{~b}}$ protein expression in cancers has been frequently related to DNA hypermethylation. ${ }^{11}$

We investigated whether epigenetic events of aberrant promoter hypermethylation in tumor suppressor genes implicated in SCCs of the head and neck underlie the pathogenesis of sinonasal papillomas. A better understanding of these lesions has clinical relevance because they can be predisposed to aggressive local behavior, recurrence, and in rare cases carcinomatous change. b Exophytic Papilloma, Case 4

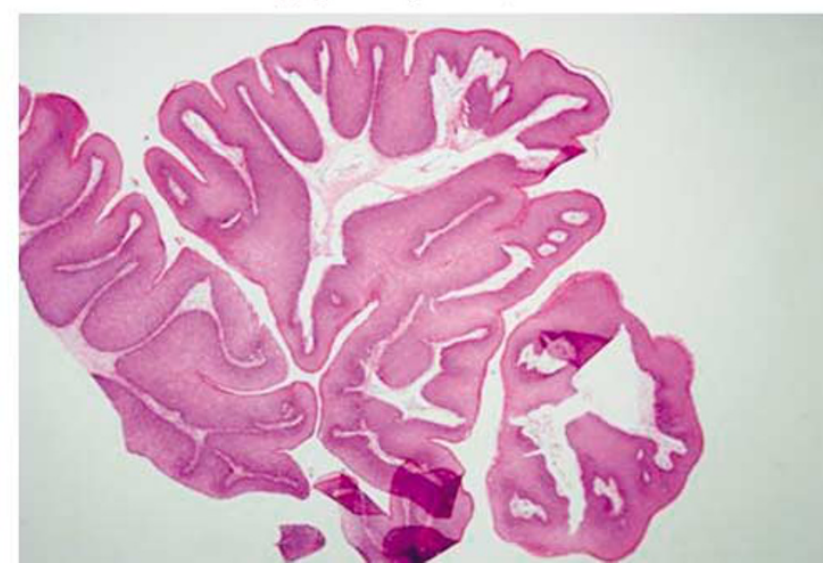

\section{Materials and methods}

\section{Papilloma Patient Cohort}

The study cohort comprised seven patients with primary and recurrent sinonasal papillomas identified in the Department of Otolaryngology, Henry Ford Health System, between the years of 1996 and 2004. The anatomic locations and histology classification for the cohort are noted in Table 1. The cohort was followed through September 2006 for further recurrent or progression events. Ten formalin-fixed paraffin DNA samples from seven cases, three inverted, two exophytic and two inverted/ exophytic were examined for promoter hypermethylation by the methylation-specific multiplex-ligation-specific polymerase assay (MS-MLPA). Cases 1 and 2 had recurrent biopsies (Table 1).

DNA was obtained from microdissected areas of normal and papilloma areas and examined using a panel of 41 gene probes designed to interrogate 35 unique genes (Table 2) with known associations to squamous head and neck cancer for aberrant methylation status (22 tumor suppressor genes) employing MS-MLPA, a modification of the conventional MLPA assay. ${ }^{12}$

\section{DNA Extraction}

Whole $5 \mu \mathrm{m}$ tissue sections or microdissected papilloma tissue and adjacent normal when present were processed for DNA extraction as described previously. ${ }^{13}$

\section{The Methylation-Specific Multiplex Ligation-Dependent Probe Amplification Assay}

The multiplex ligation-dependent probe amplification assay allows for the relative quantification of approximately 41 different DNA sequences in a single reaction requiring only $20 \mathrm{ng}$ of human DNA. 
Table 1 Clinical characteristics of cohort with MS-MLPA results

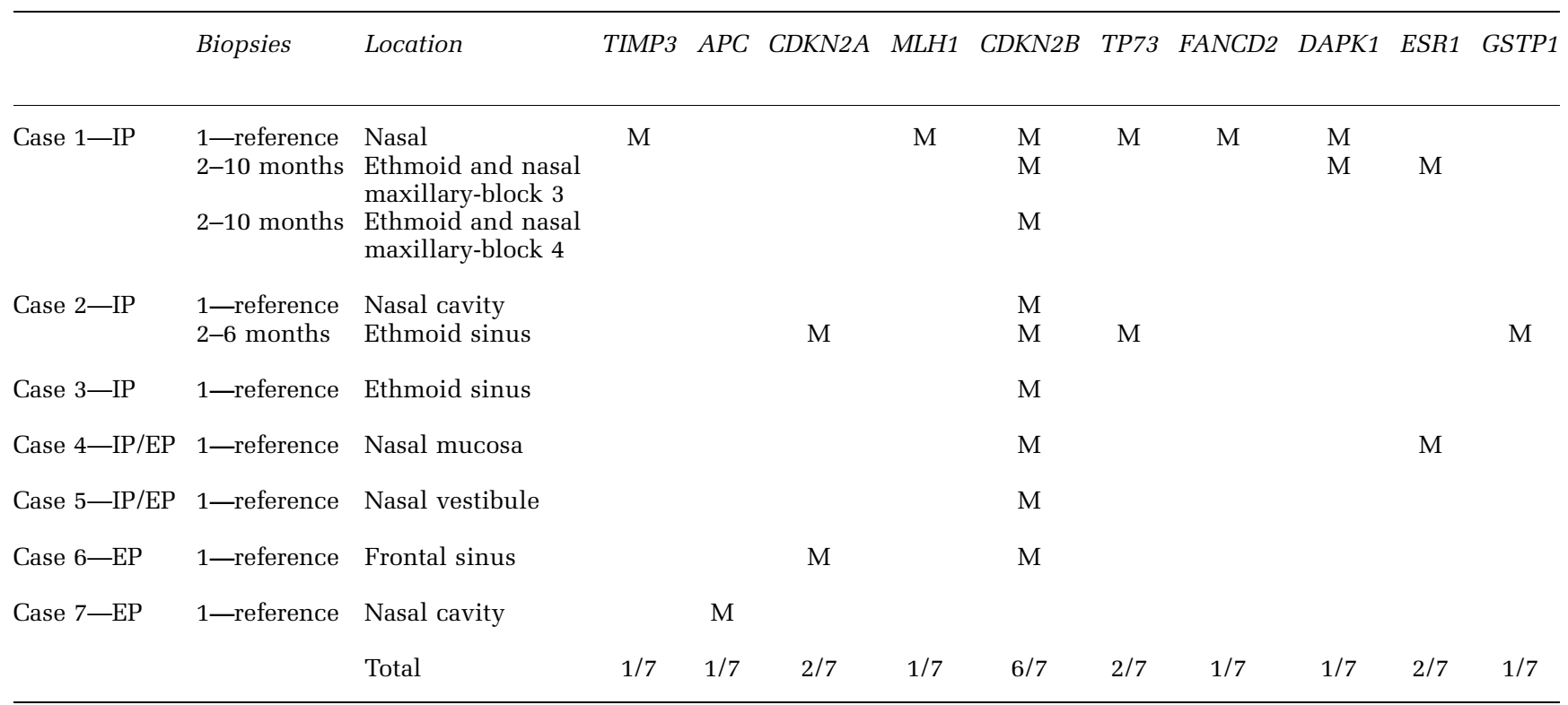

EP, exophytic papilloma; IP/EP, inverted and exophytic papilloma; IP, inverted papilloma; M, methylated.

Table 2 Methylation MLPA probe panel

\begin{tabular}{|c|c|c|c|c|c|c|c|c|c|c|c|}
\hline \multicolumn{4}{|c|}{ MLPA pilot study gene probe panel } & \multirow[t]{2}{*}{ No. } & \multirow{2}{*}{$\begin{array}{c}\text { PCR product } \\
\text { size }\end{array}$} & \multirow[t]{2}{*}{ Gene probe } & \multirow{2}{*}{$\begin{array}{l}\text { Chrom } \\
\text { Loc }\end{array}$} & \multirow[t]{2}{*}{ No. } & \multirow{2}{*}{$\begin{array}{c}\text { PCR } \\
\text { product } \\
\text { size }\end{array}$} & \multirow{2}{*}{$\begin{array}{l}\text { Gene } \\
\text { probe }\end{array}$} & \multirow{2}{*}{$\begin{array}{l}\text { Chrom } \\
\text { Loc }\end{array}$} \\
\hline No. & $\begin{array}{c}\text { PCR product } \\
\text { size }\end{array}$ & $\begin{array}{l}\text { Gene } \\
\text { probe }\end{array}$ & $\begin{array}{l}\text { Chrom } \\
\text { Loc }\end{array}$ & & & & & & & & \\
\hline \multirow[t]{3}{*}{1} & M-238 & TP73 & 01p36 & & 481 & MFHAS1 & 08p23.1 & & 310 & $R B 1$ & $13 q 14.3$ \\
\hline & 472 & NRAS & $01 \mathrm{p} 13.2$ & 12 & M-160 & $C D K N 2 A$ & 09 p21 & & 202 & MLH3 & $14 \mathrm{q} 24.3$ \\
\hline & 364 & MSH6 & 02p11 & 13 & M-427 & CDKN2A & $09 \mathrm{p} 21$ & & 283 & TSC2 & $16 \mathrm{p} 13.3$ \\
\hline 2 & M-265 & FANCD2 & $03 \mathrm{p} 26$ & 14 & M-211 & $C D K N 2 B$ & $09 \mathrm{p} 21$ & 21 & M-400 & $A S C$ & $16 p 12$ \\
\hline 3 & M-220 & VHL & 03 p26 & 15 & M-346 & DAPK1 & $09 q 34.1$ & 22 & M-247 & CDH13 & $16 q 24.2$ \\
\hline 4 & $\mathrm{M}-274$ & VHL & $03 p 26$ & & 136 & CREM & $10 \mathrm{p} 12.1$ & 23 & M-355 & HIC1 & $17 \mathrm{p} 13.3$ \\
\hline 5 & M-166 & MLH1 & $03 p 21.3$ & 16 & M-193 & MEN1 & $11 q 13$ & & 337 & BRCA1 & $17 q 21$ \\
\hline 6 & M-292 & MLH1 & $03 p 21.3$ & 17 & M-454 & GSTP1 & $11 \mathrm{q} 13$ & 24 & M-436 & BRCA1 & $17 q 21$ \\
\hline 7 & M-463 & MLH1 & $03 p 21.3$ & 18 & M-319 & IGSF4 & $11 \mathrm{q} 23$ & & 256 & BCL2 & $18 \mathrm{q} 21.3$ \\
\hline 8 & M-328 & RASSF1 & $03 p 21.3$ & & 175 & TNFRSF1A & 12p13 & 25 & M-184 & KLK10 & $19 q 13.3$ \\
\hline 9 & M-409 & FHIT & $03 \mathrm{p} 14.2$ & & 445 & TNFRSF7 & 12 p13 & & 391 & $K L K 3$ & $19 q 13$ \\
\hline \multirow[t]{2}{*}{10} & M-148 & $A P C$ & $05 q 21$ & 19 & M-382 & $C D K N 1 B$ & 12q13.1 & & 229 & NF2 & $22 q 12$ \\
\hline & 154 & $I L 4$ & $05 q 31.1$ & 20 & M-301 & BRCA2 & $13 q 12$ & 26 & M142 & TIMP3 & $22 q 12.3$ \\
\hline 11 & M-373 & ESR1 & $06 q 25.1$ & & 418 & BRCA2 & $13 q 12.3$ & & & & \\
\hline
\end{tabular}

$\square$ Probes with HhaI sites in CpG-rich promoter regions.

$\square$ Genes represented by more than one gene probe.

The standard use of the technique to observe quantitative changes in copy number has been outlined in other studies. ${ }^{14-17}$ Adaptation of the MLPA to detect aberrant methylation (MS-MLPA) has been detailed elsewhere. ${ }^{12,18-20}$

The probe design is similar to ordinary MLPA probes. For 26/41 probes, the recognition sequence detected by the MLPA probe is contained within a restriction site for the methyl-sensitive enzyme, HhaI (Figure 2). The 41 gene probe panel (Table 2) interrogates 35 unique genes implicated in cancer including HNSCC for losses and gains in a separate reaction in the absence of the methyl-sensitive enzyme HhaI. Because there are two probes each for $V H L, C D K N 2 A, B R C A 1$, and BRCA2, and three probes for $M L H 1$, a normal control DNA sample will generate 41 individual peaks in the absence of HhaI (Figures 3-5). A concurrently run reaction with the 41 gene probe set in the presence of HhaI is designed to detect aberrant promoter hypermethylation by taking advantage of a HhaI site in the promoter region of 22 of the 35 unique genes (note that one of the two BRCA1 probes is designed to recognize a region outside the HhaI recognition site, Table 2). Fifteen of the 41 gene probes are designed outside an HhaI site and serve as undigested 

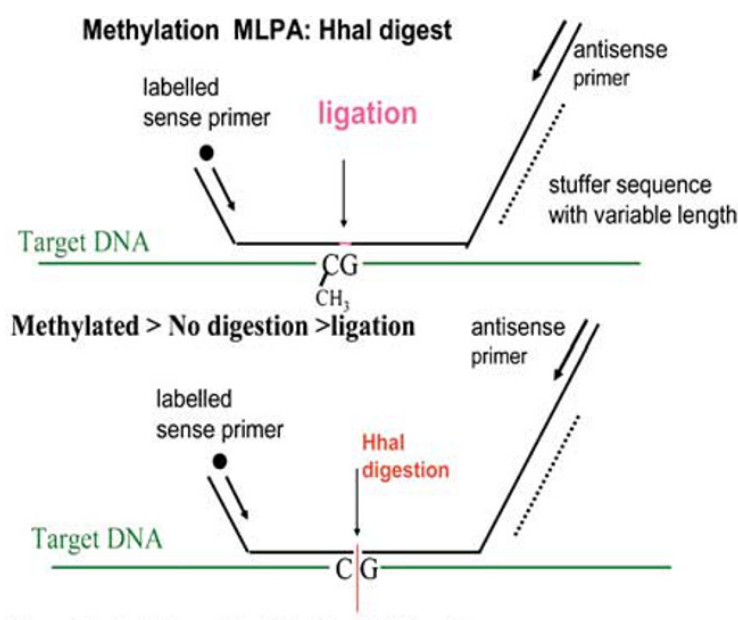

Unmethylated >cut by $\mathrm{HhaI}>$ NO ligation

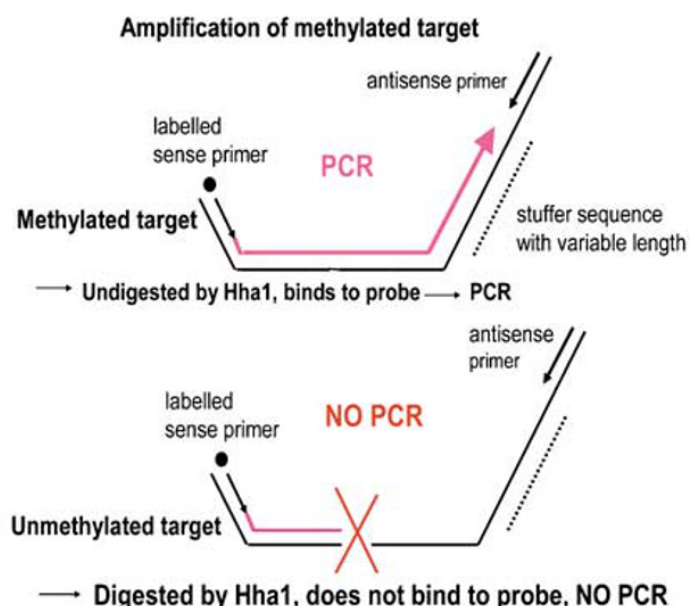

$\longrightarrow$ Digested by Hha1, does not bind to probe, NO PCR

Figure 2 Methylation-specific multiplex ligation-dependent probe amplification (see Ref. 12).

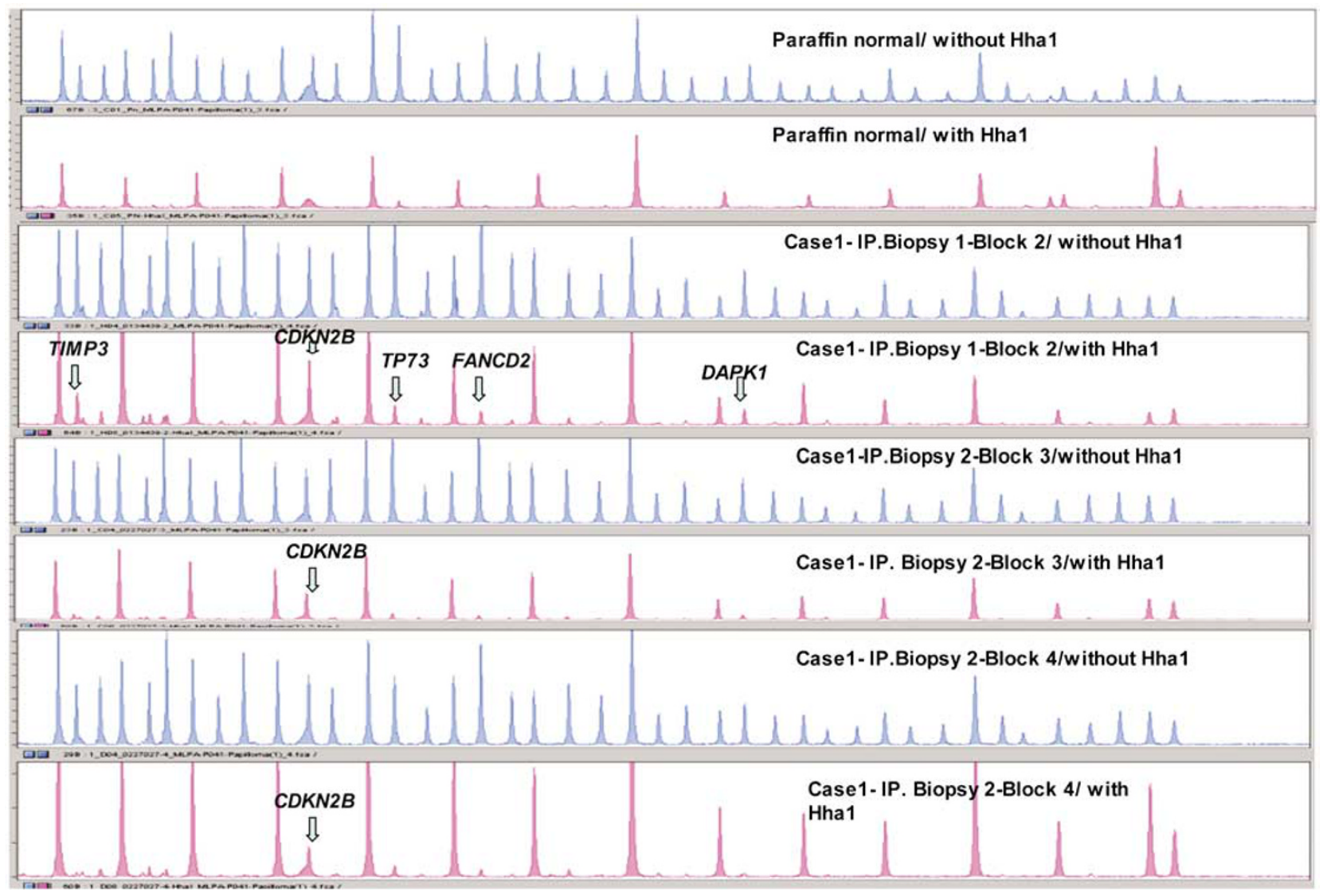

Figure 3 MS-MLPA probe mix with and without HhaI enzyme (DNA sequencer-ABI 3130). Results for Case 1-biopsy 1 block 2 and biopsy 2 blocks 3 and 4 . Note 15 peaks in the control DNA sample with HhaI. Presence of a peak in biopsies 1 and 2 (blocks 3 and 4 ) not present in the control DNA is that of aberrantly methylated $C D K N 2 B$ gene. Presence of peak for aberrantly methylated $D A P K 1$ in biopsy 1 block 2 and biopsy 2 block 3 not present in the control DNA.

controls (Figures 3-5). Upon digestion of the sample DNA with HhaI, probes that recognize the unmethylated regions will not generate a signal because these sequences have become cut by HhaI and cannot bind to the probe (Figure 2). Conversely, a MLPA probe will bind to an intact methylated site, spared by HhaI, and generate an amplification signal (Figures 2-5). Aberrant methylation is identified as the appearance of a signal peak that is otherwise absent in normal DNA samples (Figures 3-5). To quantify whether one, both, or more copies of a specific gene locus becomes aberrantly hypermethylated, a 


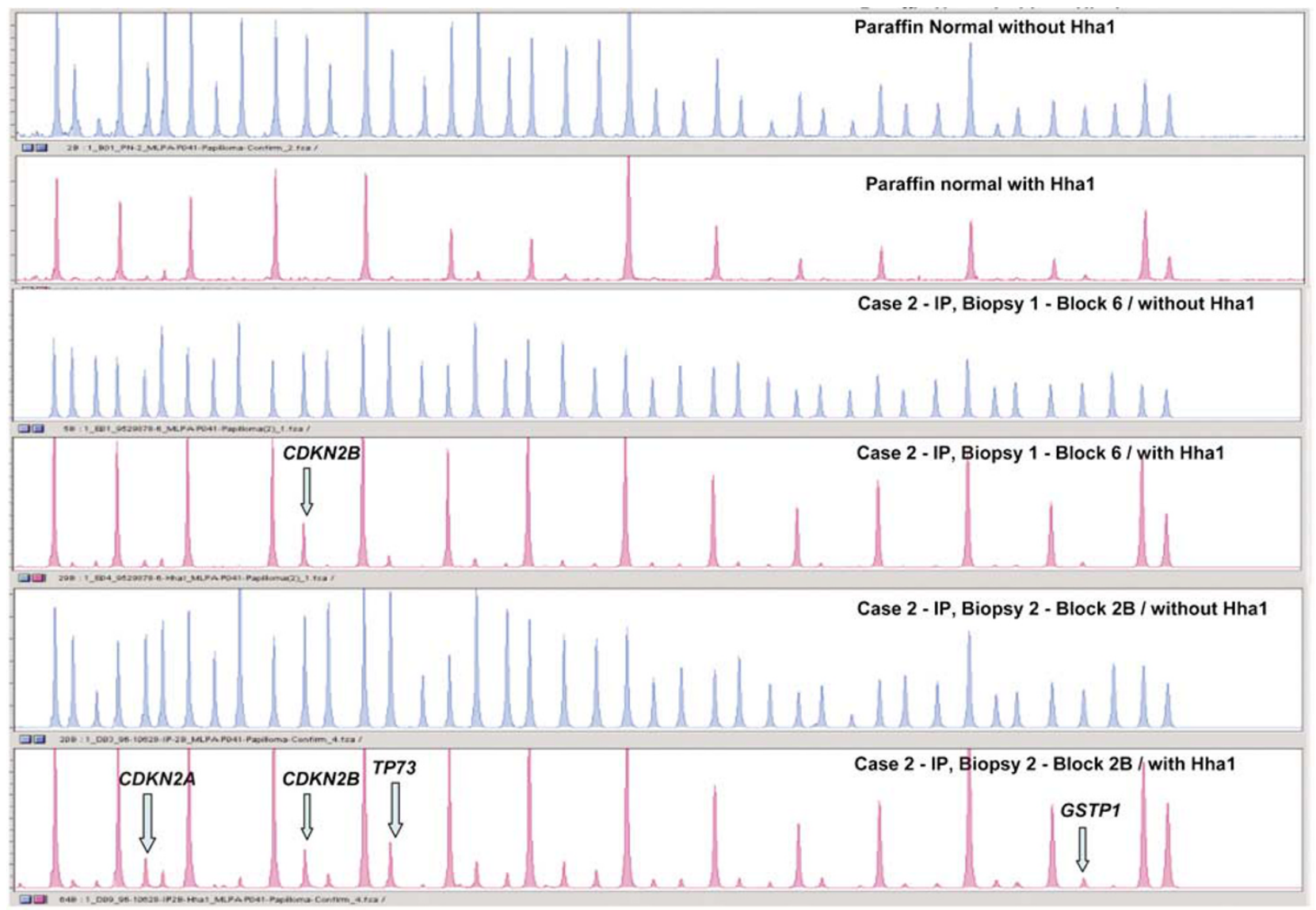

Figure 4 MS-MLPA probe mix with and without HhaI enzyme (DNA sequencer-ABI 3130). Results for Case 2-biopsy 1 block 6 and biopsy 2 block 2B. Note 15 peaks in the control DNA sample with HhaI. Presence of a peak in biopsies 1 and 2 not present in the control DNA is that of aberrantly methylated CDKN2B gene. Biopsy 2 shows additional peaks for CDKN2A, TP73 and GSTP1, which are not present in the control DNA.

previously described mathematical algorithm was employed. ${ }^{12}$

\section{Bisulfite Modification and Methylation-Specific Polymerase Chain Reaction Assay}

Genomic DNA (100 ng) from formalin-fixed paraffinembedded papilloma DNA and control universal methylated DNA (Chemicon International Inc., Temecula, CA, USA) and control unmethylated DNA (normal genomic DNA) were modified using the EZ DNA methylation kit (Zymo Research, Orange, CA, USA) during which methylated DNA is protected and unmethylated cytosine is converted into uracil. ${ }^{19}$ The modified DNA served as a template using primers specific for either the methylated or the modified unmethylated $C D K N 2 B$ sequences. $C D K N 2 B$ methylation-specific primers (MS) were sense: $5^{\prime}$-GAAGGTGCGATAGTTTTTGGA AGTCGGCGC, anti-sense; 5'-GACGATCTAAATTC CAACCCCGATCCGCCG. ${ }^{18}$ Unmethylated DNA-specific primers (UMS) were sense; 5'-TGGAGAAGGTG TGATAGTTTTTGGAAGTTGGTGT, antisense; $5^{\prime}$-CA TCAACAATCTAAATTCCAACCCCAATCCACCA. ${ }^{18}$

MSP amplification was performed using $3 \mu \mathrm{l}$ of bisulfite-modified DNA in a final volume of $25 \mu \mathrm{l}$
PCR mix containing $1 \times$ PCR buffer, $2.5 \mathrm{mM}$ dNTP, $1 \mathrm{mM} \mathrm{MgCl}{ }_{2}$ and $1 \mathrm{U}$ Amp gold Taq DNA polymerase, $0.5 \mu \mathrm{M}$ primer followed by 38 cycles at $95^{\circ} \mathrm{C}$ $45 \mathrm{~s}, 62^{\circ} \mathrm{C} 45 \mathrm{~s}, 72^{\circ} \mathrm{C} 1 \mathrm{~min}$. PCR generated a $160 \mathrm{bp}$ methylated product and a $169 \mathrm{bp}$ unmethylated product (Figure 6). The resultant PCR products were separated on $2 \%$ agarose gel stained with ethidium bromide and visualized under UV illumination (Figure 6).

\section{Results}

All seven cases indicated at least one epigenetic event of aberrant DNA hypermethylation. Ten of the 22 methylation-prone genes indicated promoter hypermethylation (Table 1). The CDKN2B gene was a consistent target of aberrant promoter hypermethylation (Figures 3-5) in six of seven cases: three inverted papillomas, two inverted/everted papillomas and one everted papilloma. Methylation-specific PCR confirmed hypermethylation of CDKN2B detected by MS-MLPA in six of seven cases (Figure 6). MSP confirmation for case 7 was not carried out due to insufficient DNA for bisulfite modification and the inability to re-extract additional DNA 


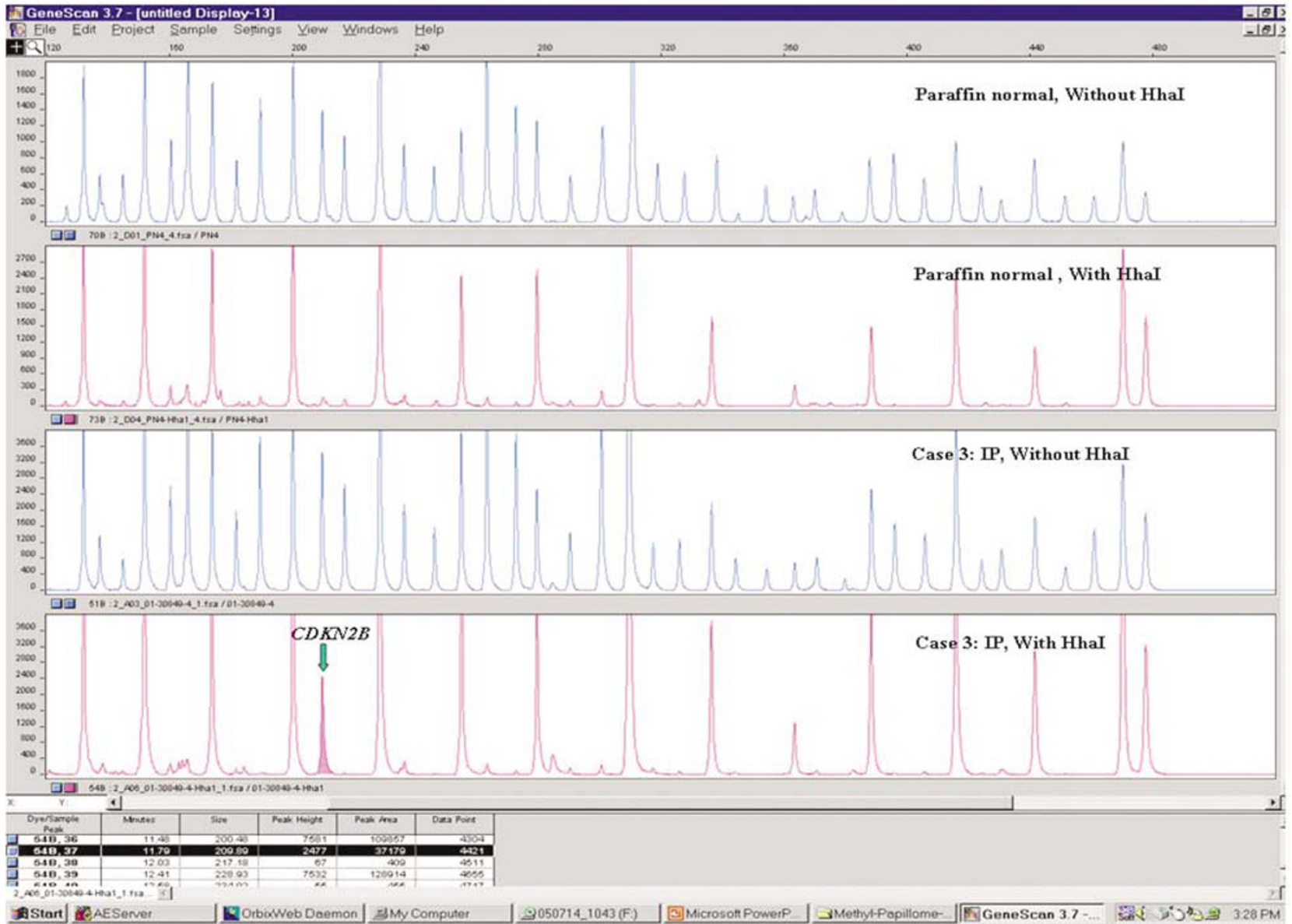

Figure 5 MS-MLPA probe mix with and without HhaI enzyme (DNA sequencer-ABI 3130). Results for case 3 . Note 15 peaks in the control DNA sample with HhaI. Presence of a peak not present in the control DNA is that of aberrantly methylated $C D K N 2 B$ gene.

MSP of CDKN2B (p15)

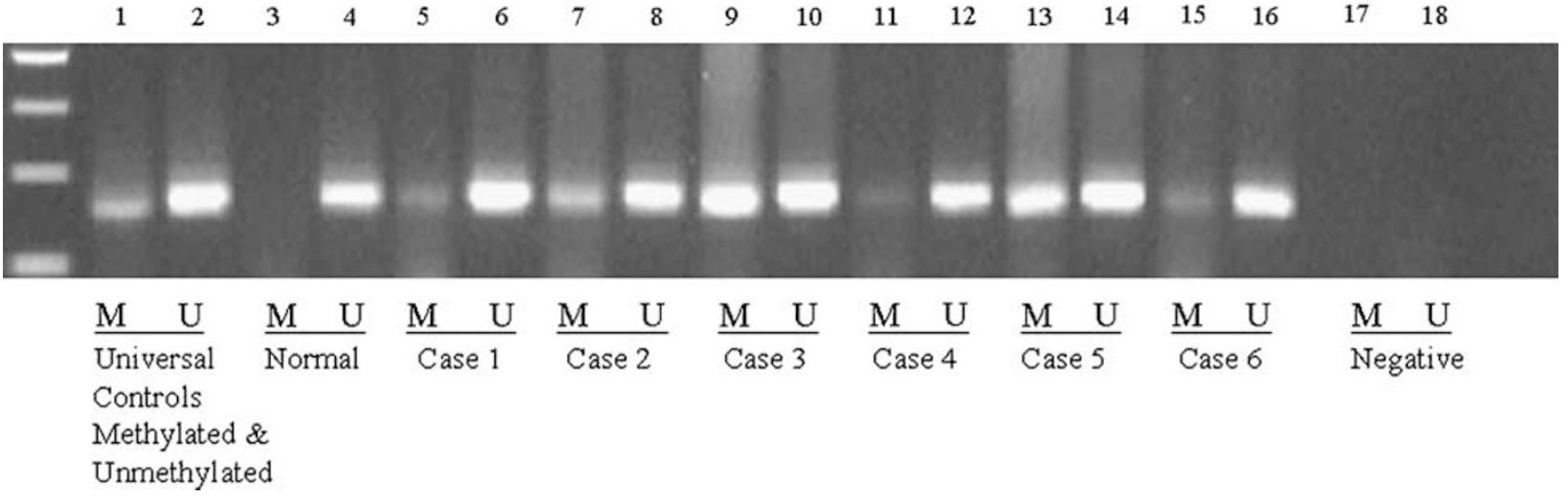

Figure 6 Methylation-specific PCR confirmation of aberrant methylation detected by MS-MLPA for CDKN2B. Lane 1: universal methylated control; lane 2: universal unmethylated control; lanes 3 and 4: normal control, note presence of only unmethylated PCR product; lanes 5-16 span cases 1-6. Note presence of methylated and unmethylated product the latter indicating admixture of normal and papilloma cells; lanes 17 and 18: negative control.

because of depletion of the tissue block. Recurrent biopsies in two inverted papilloma cases had common epigenetic events: aberrant methylation of $C D K N 2 B$ and DAPK1 in case 1, and CDKN2B in case 2 , underscoring monoclonality for these lesions.
Other commonly methylated genes include CDKN2A (2/7), TP73 (2/7), and ESR1 (2/7). TP73 was aberrantly methylated in two inverted papilloma cases. Hypermethylation of ESR1 was observed in one inverted papilloma and one inverted/everted 
papilloma. The remaining genes, TIMP3, $A P C$, MLH1, FANCD2, DAPK1, and GSTP1 were aberrantly methylated only once among the seven cases.

Follow-up of the study cohort through September 2006 did not indicate further recurrent or progression events.

\section{Discussion}

Inverted papillomas are benign, rare sinonasal lesions well known for their local recurrence, invasiveness and predisposition for malignant transformation. Recurrence rates for inverted papillomas range from 6 to $33 \%$ and malignant transformation occurs in $7-10 \%$ of cases. ${ }^{2,21}$ Endophytic sinonasal papillomas, comprising inverted papillomas and cylindrical cell papillomas according to the World Health Organization classification, show malignant progression in up to $25 \%$ of cases. ${ }^{22}$

The exact nature and biological evolution of sinonasal papillomas is not well known. Overexpression of p53 may serve as a marker for malignant transformation of inverted papilloma. ${ }^{23}$ Induction of p21waf1/cip1 is associated with terminal differentiation, senescence, and apoptosis in several tissues. ${ }^{24}$ Expression of p21waf1/cip1 has been detected in head and neck cancers, in particular oral SCCs and its precursors. ${ }^{25,26}$

Inactivation of a single allele, observed in monoclonal proliferations is usually indicative of a neoplastic process. Inverted papillomas have been shown to be monoclonal proliferations on the basis of X chromosome analysis. ${ }^{4}$ Losses at chromosomal arms 3p, 9p21, 11q13, 13q11, and 17p13 occur frequently during neoplastic transformation of the upper respiratory tract. These can be detected in SCCs and the progenitor lesions from which they arise. However, in sinonasal papillomas, loss of heterozygosity at these loci has not been detected. ${ }^{4}$ Thus, at the genomic level, inverted papillomas may not routinely harbor several of the key genetic alterations that are associated with malignant transformation.

Promoter methylation-mediated silencing is a hallmark of many established tumor suppressor genes. Aberrant methylation of promoter $\mathrm{CpG}$ islands is now recognized as an important mechanism for gene inactivation as an alternative to gene mutation or deletion in tumorigenesis. ${ }^{27,28}$ Hypermethylation of $R U N X 3$, a tumor suppressor gene, was reported in premalignant gastric lesions of chronic gastritis, intestinal metaplasia, and gastric adenomas with a progressive increase in the frequency of $R U N X 3$ methylation in gastric carcinomas. These results suggest that RUNX3 methylation increases with the progression along a multistep gastric carcinogenesis continuum to gastric carcinomas. $^{29}$

Epigenetic alterations of promoter hypermethylation have not been previously reported in sinonasal papillomas. Our candidate gene approach using MSMLPA targeted 22 tumor suppressor genes with known associations to squamous head and neck cancer to investigate whether epigenetic events of promoter hypermethylation might underlie the pathogenesis of sinonasal papillomas.

We observed aberrant methylation at the $9 p 21$ locus for $C D K N 2 B$ in six of seven and for $C D K N 2 A$ in two of seven cases. Genetic alterations at the 9p21 locus have been linked to malignant progression in HNSCC. ${ }^{16,30,31}$ The cyclin-dependent kinase $2 \mathrm{~A}$ $(C D K N 2 A)$ and $C D K N 2 B$ genes map to $9 p 21$ and are in tandem, with $C D K N 2 B$ located $25 \mathrm{~kb}$ centromeric to $C D K N 2 A .{ }^{32}$ The CDKN2A locus controls the $\mathrm{Rb}$ pathway (which regulates G1/S-phase transition) and the p53 pathway (which induces growth arrest or apoptosis in response to either DNA damage or inappropriate mitogenic stimuli by generating two gene products). ${ }^{33}$ Thus, mutations of $C D K N 2 A / \mathrm{p} 16$ inactivate the $\mathrm{Rb}$ pathway, whereas deletions of the $C D K N 2 A^{\text {INK4a }}(\mathrm{p} 16)$ and $C D K N 2 A^{\mathrm{ARF}}$ (p14) genes alter both the $\mathrm{Rb}$ and $\mathrm{p} 53$ pathways which are important in many cancers. Cyclin-dependent kinase inhibitor $2 \mathrm{~B}(C D K N 2 B)$, which is also known as p15, inhibits CDK4 and regulates cell growth by controlling cell-cycle G1 progression. ${ }^{34}$

Inactivation of the $C D K N 2 B$ (p15) and $C D K N 2 A$ ( $p 14$ and $p 16$ ) genes at the genomic and epigenetic level is a frequent event in human oral SCCs and in HNSCC. ${ }^{12,14,35}$ One study reported aberrant methylation of $C D K N 2 B(p 15)$ and $C D K N 2 A(p 16)$ in more than $50 \%$ of the oral SCCs. ${ }^{36}$ The presence of aberrant methylation of p15 and p16 in precancerous oral tissues ${ }^{35}$ implicates methylation of p15 and p16 as early events in the pathogenesis of oral lesions. In undifferentiated nasopharyngeal carcinoma (NPC), preferential methylation of $C D K N 2 B$ has been shown to be a useful tumor marker for NPC. ${ }^{37}$

Other commonly methylated genes include TP73 (2/7 cases) and ESR1 (2/7 cases). TP73, located at 1 p36.3, is involved in cell-cycle regulation, and is frequently deleted in many types of human tumors. ${ }^{38-40}$ TP73 codes a product which has significant structural homology to the TP53 gene product in the domains involving transactivation, DNA binding and oligomerization. ${ }^{41}$ Functionally, the TP73 gene product is able to activate the TP53responsive proteins, inhibit cell growth and induce apoptosis. ${ }^{42}$ Hypermethylation of TP73 in NPCs has been reported with a frequency of $20 \% .{ }^{37}$ In head and neck SCC, hypermethylation of TP73 occurred as a primary as well as a disease progression event. ${ }^{12}$

Estrogen receptor 1 (ESR1), maps to 6q25.1 and is important for hormone binding, DNA binding, and activation of transcription. ${ }^{43}$ ESR1 has metastasissuppressor properties in breast cancer cells, ${ }^{44}$ suggesting a tumor-suppressor role for ESR1. ${ }^{45}$ ESR1 is methylated in Barrett's metaplastic and dysplastic samples and in some adenocarcinoma samples. In esophageal adenocarcinomas, abnormal 
methylation patterns were found in premalignant Barrett's tissue in addition to adenocarcinoma tissue suggesting that DNA hypermethylation is an early epigenetic event in the progression of esophageal adenocarcinomas. ${ }^{46}$ Of the two cases where ESR1 was methylated in our cohort, one was an inverted papilloma and the other an inverted papilloma/ everted papilloma.

Our novel genome-wide strategy identified several genes with aberrant promoter hypermethylation. Recurrent genomic aberrations are good indicators of genes that are causally associated with cancer development or progression and either become or reveal gene targets for therapy. Frequently, methylated genes in this sinonasal papilloma cohort included CDKN2B, CDKN2A, TP73, and ESR1.

In this sinonasal papilloma cohort, the $C D K N 2 B$ gene, a chromosome 9p21 locus resident was a common epigenetic target. Persistence of aberrant hypermethylation of common epigenetic events in recurrent biopsies (cases 1 and 2) underscored a monoclonal origin for inverted papilloma. These findings support a role for epigenetic events of promoter hypermethylation in the pathogenesis of benign inverted and exophytic papillomas. As a consistent target of aberrant promoter hypermethylation, $C D K N 2 B$ may serve as a useful biomarker and a potential therapeutic target for gene reactivation studies and in disease monitoring for progression, similar to serum SCC antigen level monitoring of inverted papilloma status. ${ }^{47}$ In the latter, serum SCC antigen levels in patients with gynecologic, head and neck, lung, and esophageal SCCs are elevated and it has been widely used as a tumor marker with the potential for monitoring the course of disease.

Promoter methylation-mediated silencing is a hallmark of many established tumor suppressor genes. An important distinction between genetic and epigenetic changes in cancer is that the latter might be more easily reversed using therapeutic interventions. Because gene silencing, as a consequence of promoter hypermethylation, can be partially relieved by demethylation of the promoter region, ${ }^{27,28}$ the molecules that regulate methylation status of DNA are considered promising targets for new cancer therapies. Identifying epigenetic alterations in benign sinonasal papillomas may lead to the discovery of biomarkers that aid in the diagnosis and prognosis of sinonasal papillomas.

\section{Acknowledgement}

This work was supported by NIH RO1 DE15990 (MJW).

\section{Disclosure/conflict of interest}

There are no conflicts of interest for any of the authors.

\section{References}

1 Hyams VJ. Papillomas of the nasal cavity and paranasal sinuses. A clinicopathological study of 315 cases. Ann Otol Rhinol Laryngol 1971;80:192-206.

2 Batsakis JG, Suarez P. Schneiderian papillomas and carcinomas: a review. Adv Anat Pathol 2001;8: 53-64.

3 Wormald PJ, Ooi E, van Hasselt CA, et al. Endoscopic removal of sinonasal inverted papilloma including endoscopic medial maxillectomy. Laryngoscope 2003;113:867-873.

4 Califano J, Koch W, Sidransky D, et al. Inverted sinonasal papilloma: a molecular genetic appraisal of its putative status as a Precursor to squamous cell carcinoma. Am J Pathol 2000;156:333-337.

5 Buchwald C, Franzmann MB, Jacobsen GK, et al. Human papillomavirus (HPV) in sinonasal papillomas: a study of 78 cases using in situ hybridization and polymerase chain reaction. Laryngoscope 1995;105: 66-71.

6 Brandwein M, Steinberg B, Thung S, et al. Human papillomavirus 6/11 and 16/18 in Schneiderian inverted papillomas. In situ hybridization with human papillomavirus RNA probes. Cancer 1989;63: 1708-1713.

7 Buchwald C, Lindeberg H, Pedersen BL, et al. Human papilloma virus and p53 expression in carcinomas associated with sinonasal papillomas: a Danish Epidemiological study 1980-1998. Laryngoscope 2001;111: 1104-1110.

8 Syrjanen KJ. HPV infections in benign and malignant sinonasal lesions. J Clin Pathol 2003;56:174-181.

9 Syrjanen S, Happonen RP, Virolainen E, et al. Detection of human papillomavirus (HPV) structural antigens and DNA types in inverted papillomas and squamous cell carcinomas of the nasal cavities and paranasal sinuses. Acta Otolaryngol 1987;104: 334-341.

10 Katori H, Nozawa A, Tsukuda M. Markers of malignant transformation of sinonasal inverted papilloma. Eur J Surg Oncol 2005;31:905-911.

11 Herman JG, Merlo A, Mao L, et al. Inactivation of the CDKN2/p16/MTS1 gene is frequently associated with aberrant DNA methylation in all common human cancers. Cancer Res 1995;55:4525-4530.

12 Worsham MJ, Chen KM, Meduri V, et al. Epigenetic events of disease progression in head and neck squamous cell carcinoma. Arch Otolaryngol Head Neck Surg 2006;132:668-677.

13 Raju ULM, Sethi S, Qureshi H, et al. Molecular classification of breast carcinoma in situ. Current Genomics 2006;7:523-532.

14 Worsham MJ, Pals G, Schouten JP et al. Delineating genetic pathways of disease progression in head and neck squamous cell carcinoma. Arch Otolaryngol Head Neck Surg 2003;129:702-708.

15 Worsham MJ, Pals G, Schouten JP, et al. Highresolution mapping of molecular events associated with immortalization, transformation, and progression to breast cancer in the MCF10 model. Breast Cancer Res Treat 2006;96:177-186.

16 Worsham MJ, Chen KM, Tiwari N, et al. Fine-mapping loss of gene architecture at the CDKN2B (p15INK4b), CDKN2A (p14ARF, p16INK4a) and MTAP genes in head and neck squamous cell carcinoma. Arch Otolaryngol Head Neck Surg 2006;132:409-415. 
17 Kunjoonju JP, Raitanen M, Grenman S, et al. Identification of individual genes altered in squamous cell carcinoma of the vulva. Genes Chromosomes Cancer 2005;44:185-193.

18 Nygren AO, Ameziane N, Duarte HM, et al. Methylation-specific MLPA (MS-MLPA): simultaneous detection of $\mathrm{CpG}$ methylation and copy number changes of up to 40 sequences. Nucleic Acids Res 2005;33:e128.

19 Worsham MJ, Chen KM, Sawheny R, et al. Methylation of multiple genes as diagnostic and therapeutic markers in primary HNSCC. Arch Otolaryngol Head Neck Surg (in press).

20 Stephen JK, Vaught LE, Chen KM, et al. An epigenetically derived monoclonal origin for recurrent respiratory papillomatosis. Arch Otolaryngol Head Neck Surg 2007;133:684-692.

21 Lawson W, Kaufman MR, Biller HF. Treatment outcomes in the management of inverted papilloma: an analysis of 160 cases. Laryngoscope 2003;113: 1548-1556.

22 Lawson W, Ho BT, Shaari CM et al. Inverted papilloma: a report of 112 cases. Laryngoscope 1995;105: 282-288.

23 Gujrathi C, Pathak I, Freeman J, et al. Expression of p53 in inverted papilloma and malignancy associated with inverted papilloma. J Otolaryngol 2003;32:48-50.

24 el-Deiry WS. p21/p53, cellular growth control and genomic integrity. Curr Top Microbiol Immunol 1998; 227:121-137.

25 Yook JI, Kim J. Expression of p21WAF1/CIP1 is unrelated to p53 tumour suppressor gene status in oral squamous cell carcinomas. Oral Oncol 1998;34: 198-203.

$26 \mathrm{Ng}$ IO, Lam KY, Ng M, et al. Expression of p21/waf1 in oral squamous cell carcinomas-correlation with p53 and mdm2 and cellular proliferation index. Oral Oncol 1999;35:63-69.

27 Baylin SB, Herman JG, Graff JR, et al. Alterations in DNA methylation: a fundamental aspect of neoplasia. Adv Cancer Res 1998;72:141-196.

28 Jones PA, Laird PW. Cancer epigenetics comes of age. Nat Genet 1999;21:163-167.

29 Kim TY, Lee HJ, Hwang KS, et al. Methylation of RUNX3 in various types of human cancers and premalignant stages of gastric carcinoma. Lab Invest 2004;84:479-484.

30 Danahey DG, Tobin EJ, Schuller DE, et al. p16 mutation frequency and clinical correlation in head and neck cancer. Acta Otolaryngol 1999;119:285-288.

31 Lydiatt WM, Davidson BJ, Schantz SP, et al. 9p21 deletion correlates with recurrence in head and neck cancer. Head Neck 1998;20:113-118.

32 Sherr CJ. Cancer cell cycles. Science 1996;274: 1672-1677.
33 Xing EP, Nie Y, Song Y, et al. Mechanisms of inactivation of p14ARF, p15INK4b, and p16INK4a genes in human esophageal squamous cell carcinoma. Clin Cancer Res 1999;5:2704-2713.

34 Hannon GJ, Beach D. p15INK4B is a potential effector of TGF-beta-induced cell cycle arrest. Nature 1994; 371:257-261.

35 Shintani S, Nakahara Y, Mihara M, et al. Inactivation of the p14(ARF), p15(INK4B) and p16(INK4A) genes is a frequent event in human oral squamous cell carcinomas. Oral Oncol 2001;37:498-504.

36 Yeh KT, Chang JG, Lin TH, et al. Epigenetic changes of tumor suppressor genes, P15, P16, VHL and P53 in oral cancer. Oncol Rep 2003;10:659-663.

37 Wong TS, Tang KC, Kwong DL, et al. Differential gene methylation in undifferentiated nasopharyngeal carcinoma. Int J Oncol 2003;22:869-874.

38 White PS, Maris JM, Beltinger C, et al. A region of consistent deletion in neuroblastoma maps within human chromosome 1p36.2-36.3. Proc Natl Acad Sci USA 1995;92:5520-5524.

39 Nagai H, Negrini M, Carter SL, et al. Detection and cloning of a common region of loss of heterozygosity at chromosome $1 \mathrm{p}$ in breast cancer. Cancer Res 1995; 55:1752-1757.

40 Weith A, Martinsson T, Cziepluch C, et al. Neuroblastoma consensus deletion maps to 1p36.1-2. Genes Chromosomes Cancer 1989;1:159-166.

41 Dong S, Pang JC, Hu J, et al. Transcriptional inactivation of TP73 expression in oligodendroglial tumors. Int J Cancer 2002;98:370-375.

42 Kaghad M, Bonnet H, Yang A, et al. Monoallelically expressed gene related to p53 at 1p36, a region frequently deleted in neuroblastoma and other human cancers. Cell 1997;90:809-819.

43 Ponglikitmongkol M, Green S, Chambon P. Genomic organization of the human oestrogen receptor gene. EMBO J 1988;7:3385-3388.

44 Garcia M, Derocq D, Freiss G, et al. Activation of estrogen receptor transfected into a receptor-negative breast cancer cell line decreases the metastatic and invasive potential of the cells. Proc Natl Acad Sci USA 1992;89:11538-11542.

45 Issa JP, Ottaviano YL, Celano P, et al. Methylation of the oestrogen receptor $\mathrm{CpG}$ island links ageing and neoplasia in human colon. Nat Genet 1994;7:536-540.

46 Eads CA, Lord RV, Kurumboor SK, et al. Fields of aberrant $\mathrm{CpG}$ island hypermethylation in Barrett's esophagus and associated adenocarcinoma. Cancer Res 2000;60:5021-5026.

47 Yasumatsu R, Nakashima T, Masuda M, et al. Clinical value of serum squamous cell carcinoma antigen in the management of sinonasal inverted papilloma. Head Neck 2005;27:44-48. 